\title{
Impact of the shape of the implantable ports on their efficiency of flow (injection and flushing)
}

\author{
This article was published in the following Dove Press journal: \\ Medical Devices: Evidence and Research \\ 17 September 2014 \\ Number of times this article has been viewed
}

\author{
Gérard Guiffant ${ }^{\prime}$ \\ Patrice Flaud' \\ Jean Jacques Durussel' \\ Jacques Merckx ${ }^{1,2}$ \\ 'Université Paris Diderot, Paris, \\ France; ${ }^{2}$ University Teaching Hospital \\ Necker-Enfants Malades, Paris, France
}

\begin{abstract}
Now widely used, totally implantable venous access devices allow mid- and long-term, frequent, repeated, or continuous injection of therapeutic products by vascular, cavitary, or perineural access. The effective flushing of these devices is a key factor that ensures their long-lasting use. We present experimental results and a numerical simulation to demonstrate that the implementation of rounded edge wall cavities improves flushing efficiency. We use the same approaches to suggest that the deposit amount may be reduced by the use of rounded edge wall cavities.
\end{abstract}

Keywords: implantable ports, totally implantable venous access devices, flushing, obstruction, prevention

\section{Introduction}

For more than three decades, totally implantable venous access devices (TIVADs) have been used for drug administration (injection or perfusion), as well as for blood collection. These devices have been proven to be safe and effective in overcoming problems due to repeated venous access. Furthermore, their characteristics, risks, benefits, usage settings, and maintenance are well described and detailed in various protocols and papers in the literature. ${ }^{1-11}$

TIVADs are designed to permit repeated injections, repeated infusions, and occasional blood samples; these devices require regular care by repeated flushing. Previous articles have shown that the direction and nature of the flow - stationary or nonstationary - have an impact on the storage and withdrawal of the infusion residue. ${ }^{12-14}$ In spite of the maintenance of these ports, sites of stored deposits remain factors for occlusion and for bacterial or fungal colonization. Determining the best conditions for port maintenance is definitely a key parameter when trying to benchmark the functional performances of ports from different manufacturers. ${ }^{15,16}$ From a geometrical point of view, the different ports are quite similar, except that their sizes correspond to different therapeutic applications, implantation locations, and ages of patients. The port is a cylindrical cavity closed by a deformable septum and opens through either an outlet canal or extending stem to a parenteral catheter. Though mentioned in previous studies, the impact of the outlet canal's orientation, tangential or perpendicular, remains unclear because, the geometrical flow conditions downstream of the injection are known to have no or poor effects on the upstream flow. ${ }^{15}$

The purpose of this study is to show that the geometric cavity design may have an impact on the processes of depositing and flushing in the maintenance of TIVADs. In particular, we show that removing sharp edges between basal and lateral surfaces
Correspondence: Gérard Guiffant Université Paris Diderot, Centre National de la Recherche Scientifique (CNRS) 7057, 10 rue Alice Domon et Léonie Duquet, 75205 Paris, CEDEX 13, France

$\mathrm{Fax}+330157276211$

Email gerard.guiffant@univ-paris-diderot.fr 
has a significant effect on the efficiency of flow during injections.

\section{Materials and methods}

The study was conducted with ports of internal volumes of $0.2 \mathrm{~mL}$ and $0.5 \mathrm{~mL}$, and with both straight and curved sidewalls. The ports with straight sidewalls were chosen anonymously as representative of the most commonly used ports. The ports with curved sidewalls were supplied by AngioDynamics. The two types of AngioDynamics Vortex ${ }^{\circledR}$ ports tested were the Smart Port ${ }^{\circledR}$ CT Mini (volume $0.2 \mathrm{~mL}$ ) and the Vortex ${ }^{\circledR}$ TR Low Profile (volume $0.5 \mathrm{~mL}$ ).

The primary aim is to report experimental data regarding the hydrodynamic flushing efficiency in controlled flow conditions. The method used in this study was the same one that was used in previous studies. ${ }^{12-14}$

Each port was filled with an aqueous solution of $0.1 \%$ dodecyl sulfate sodium by a syringe, and a Huber needle was inserted in the septum center. After an incubation period of 48 hours at $37^{\circ} \mathrm{C}$, the ports were emptied and flushed with $30 \mathrm{~mL}$ of pure water through a sloped outflow channel to completely washout the dodecyl sulfate sodium.

Once cleansed, each port was filled with a $5 \mu \mathrm{g} / \mathrm{mL}$ aqueous solution of fibronectin (Sigma-Aldrich Co, St Louis, MO, USA) and kept for 2 hours at $37^{\circ} \mathrm{C}$. The nonadherent fibronectin was eliminated by a slow injection of air through the Huber needle. A $10 \mathrm{mg} / \mathrm{mL}$ saline solution of bovine serum albumin (Sigma-Aldrich Co) was then injected, and the ports were incubated for 24 hours at $37^{\circ} \mathrm{C}$. One again, each port was flushed with a slow injection of air through the Huber needle in order to eliminate the nonadherent bovine serum albumin. The recovered amount was titrated. Fibronectin and albumin were selected because both are physiological blood proteins. Furthermore, fibronectin easily and strongly adheres to biomaterials and blood products, and it also promotes the adhesion of albumin and other proteins. The ports were flushed with $10 \mathrm{~mL}$ of $0.9 \% \mathrm{NaCl}$ at $0.5 \mathrm{~mL} / \mathrm{second}$ by an autopulsed syringe locked to the $22 \mathrm{G}$ Huber needle (Polyperf $^{\circledR}$; Perouse Medical, Ivry-le-Temple, France).

A series of tridimensional numerical simulations were performed using $\mathrm{COMSOL}^{\circledR}$, allowing for flow visualization in the ports, as well as to determine the distributions of the wall shear stress. Wall shear stress is responsible for both the wall deposits and efficiency of flushing.

\section{Statistical analysis}

The Mann-Whitney $U$-test was used on means (number $[\mathrm{N}]=6$ ). Statistical significance thresholds are shown on the figures using the classical correspondence: * for $0.01<P<0.05$, $* *$ for $0.001<P<0.01$, and $* * *$ for $P<0.001$.

\section{Experimental results}

Figure 1 shows a bidimensional schematic representation of a port, indicating the two retained angles $\alpha$ for the needle bevel orientation (namely, $\alpha=0^{\circ}$ and $\alpha=180^{\circ}$ ) with respect to the port output. The major experimental results are summarized in Figure 2, which shows the mean percentage of extracted proteins for each type of implantable port size under the conditions considered for this experiment. These experimental results show that all things being equal, the flushing is significantly more effective in a curved sidewall port than in a straight sidewall port. Figure 3 shows the experimental results for the two curved sidewalls ports that were tested. The flushing efficiency was higher when the Huber needle was inserted at an $\alpha$ of $180^{\circ}$ than when it was inserted at an $\alpha$ of $0^{\circ} .^{13}$

\section{Numerical simulations}

We consider that the flushing of a curved sidewall port is more favorable than the flushing of a straight sidewall port. It is the aim of this section to show that this advantage is the result of the greater hydrodynamic friction in a curved sidewall port than in a straight sidewall port. From this point of view, it is clear that the aim of the simulation is not to give an exact representation of the AngioDynamics Vortex ${ }^{\circledR}$ ports or the straight sidewall ports used in the experimental bench tests. A numerical tridimensional simulation using $\mathrm{COMSOL}^{\circledR}$ was performed to show how both the flow and hydrodynamic friction are distributed in a port when the flushing flow is injected into the port. Figure $4 \mathrm{~A}$ and $\mathrm{B}$ show the geometry retained for the simulation. For better practical

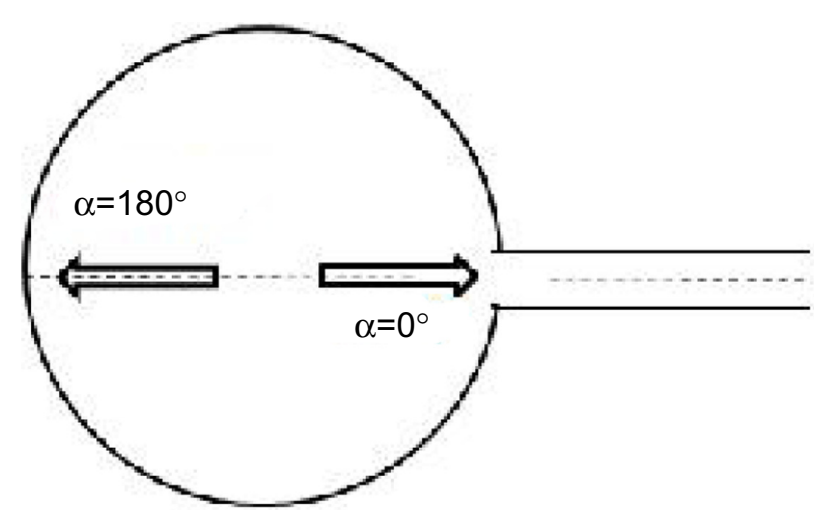

Figure I Bidimensional schematic representation of the cavity.

Notes: Arrows indicate the two directions of the needle bevel opening for the input flow. The needle bevel orientation with respect to the port output is represented by $\alpha$. 


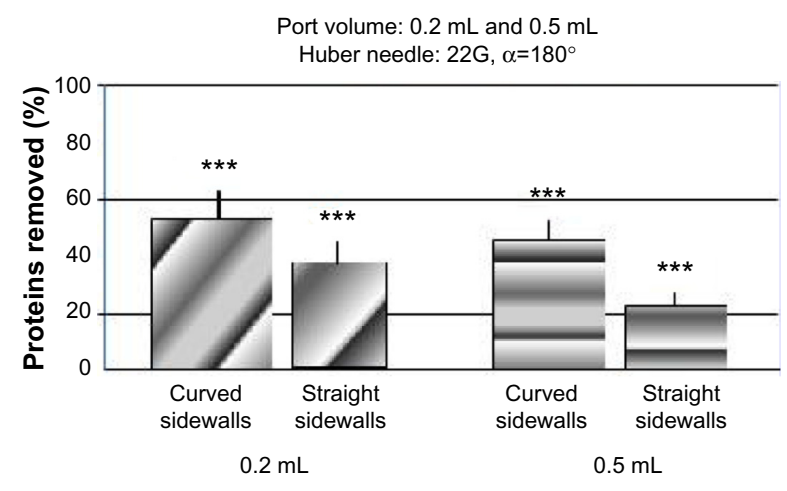

Figure 2 Percentage of proteins removed from ports of inner volumes $0.2 \mathrm{~mL}$ and $0.5 \mathrm{~mL}$ for curved sidewalls and straight sidewalls.

Notes: The needle bevel orientation with respect to the port output is represented by $\alpha$. The values are significant at $P<0.001$ (***).

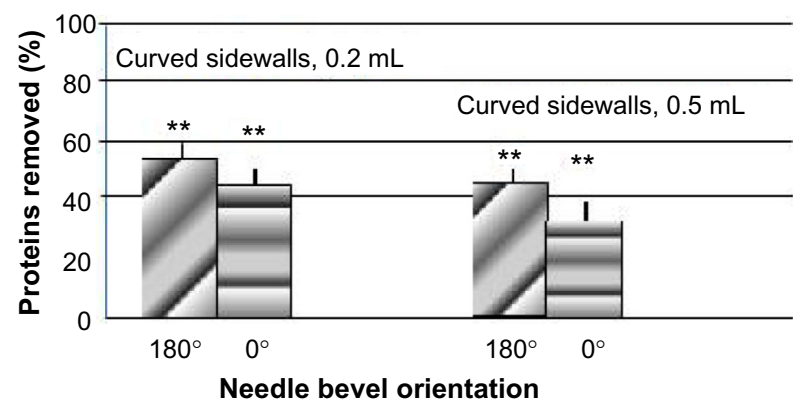

Figure 3 Percentage of proteins removed in curved sidewall ports of inner volume $0.2 \mathrm{~mL}$ and $0.5 \mathrm{~mL}$ for the two directions of the needle bevel opening.

Notes: The directions of the needle bevel opening are relative to the port output. The values are significant at $0.00 \mathrm{I}<P<0.0 \mathrm{I}(* *)$
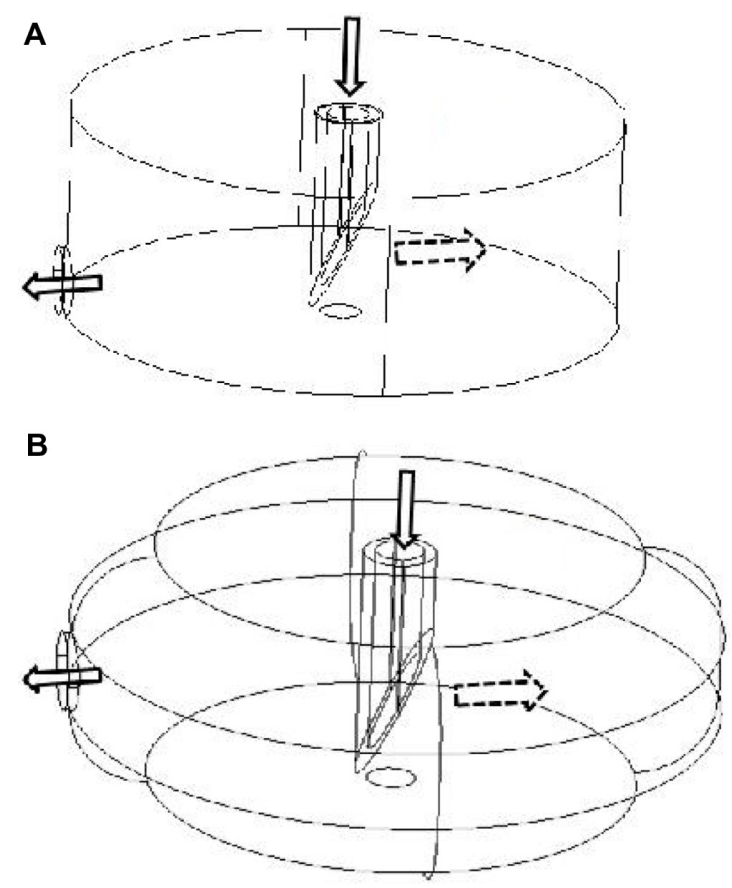

Figure 4 Tridimensional representation of the shape of the cavities. Notes: Straight sidewalls $(\mathbf{A})$ and rounded sidewalls $(\mathbf{B})$. The arrow with dotted lines indicates the direction of the needle bevel opening with respect to the port output. The solid line arrows indicate the direction of input and output flows.
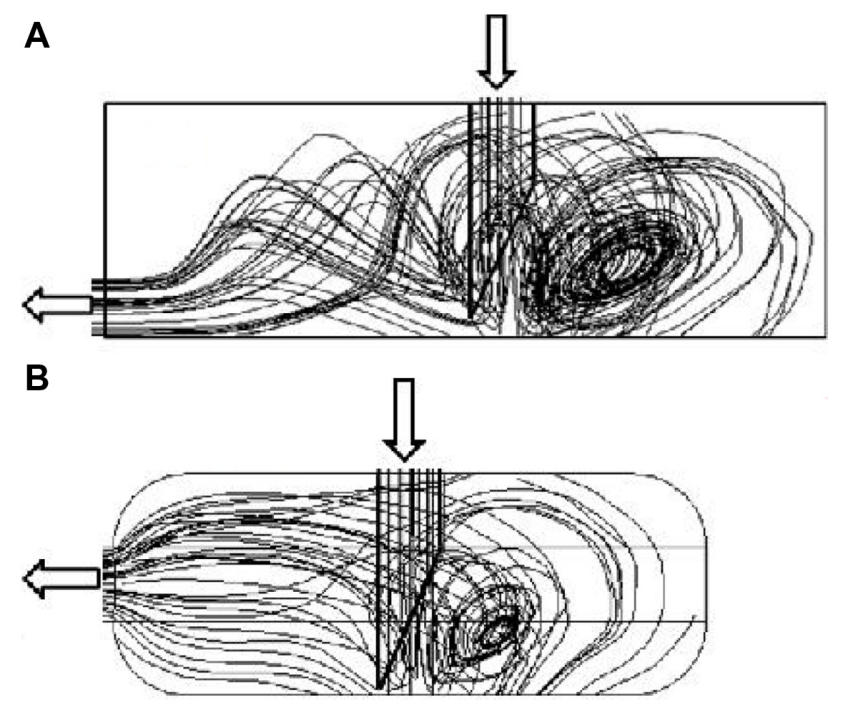

Figure $\mathbf{5}$ Representation of the lines of flow in the median plane of symmetry. Notes: Straight sidewall cavity (A) and rounded sidewall cavity (B). The solid line arrows indicate the direction of input and output flows.

conditions, the bevel of the Huber needle is orientated opposite to the outlet, as shown by the arrow with dotted lines in Figure $4 \mathrm{~A}$ and B. Figure $5 \mathrm{~A}$ and $\mathrm{B}$ show two examples of the lines of flow in a median plane of symmetry of the two chambers considered. The results shown were obtained for a mean input velocity of $50 \mathrm{~cm} / \mathrm{second}$. It is clear that the flows inside the cavities are similar in both cases and exhibit a main recirculation flow in the vicinity of the Huber needle output. This main flow structure is poorly affected when the input flow is varied. The flow structure is typical and is commonly referred to as "cavity flow", and is the subject of many practical and theoretical developments. The point to be emphasized is that the distribution of the hydrodynamic shear stress on the cavity walls is responsible for the wall friction (due to the fluid viscosity) and is, therefore, the key for flushing efficiency (or deposit removal in the
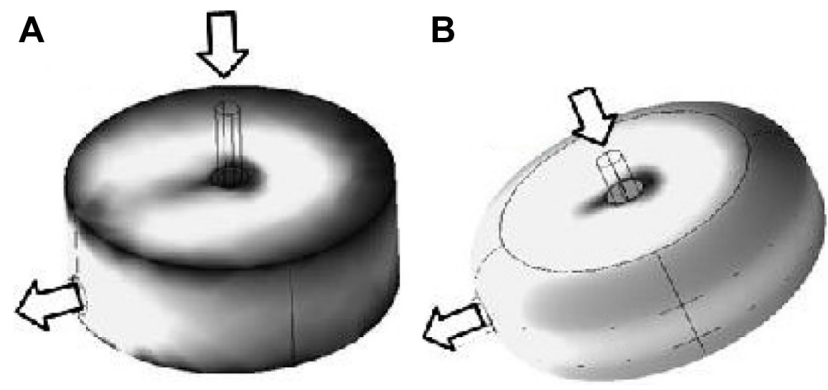

Figure 6 Tridimensional representation of the intensity of the wall shear stress on the cavities.

Notes: Straight side wall cavity $(\mathbf{A})$ and rounded side wall cavity $(\mathbf{B})$. The arrows indicate the direction of input and output flows. The intensity of the shear stress is represented by a gray scale. The color white is associated with high shear stress values and the color black with low shear stress values. 
Table I Values of the coefficient $C$ for the different shapes of implantable ports

\begin{tabular}{ll}
\hline Port shape & C \\
\hline Curved sidewall & 0.0003 \\
Straight sidewall & 0.0400 \\
Straight sidewall with a rounded edge & 0.0300 \\
\hline
\end{tabular}

Note: $\mathrm{C}=$ (the port's surface area that undergoes a wall shear stress $<10$ seconds ${ }^{-1}$ )/ (the port's total surface area).

case of injection). Figure $6 \mathrm{~A}$ and $\mathrm{B}$ show a tridimensional representation of the intensity of the wall shear stress on cavities. The intensity of the shear stress is represented by a gray scale in which the color white is associated with high values of shear stress and the color black with the low ones. It is clear that the wall shear stress repartition is significantly different in both cases and, thus, has to be related to the significant differences observed in the flushing efficiency that are reported in Figure 2. The shape of the cavity has a significant influence on the wall shear stress distribution in the cavity and, therefore, a significant influence on the input flow.

It is obviously tempting to try to define a macroscopic global parameter for the potential cavity flushing efficiency. It is reasonable to expect that the intensity of the wall shear stress has to be sufficient to ensure effective flushing. Then, a qualitative coefficient can be defined by the ratio of the surface area on which the wall shear stress intensity is less than a given value to the total surface area of the cavity. Such a coefficient has clearly no intrinsic value because the choice of the threshold value of the wall shear stress intensity is arbitrary. The interest of such a procedure is to allow a comparison between cavities, all things being equal.

Table 1 shows an example of a set of values obtained with a threshold value of the wall shear stress as 10 seconds $^{-1}$. The simulation shows that the fraction of the wall surface undergoing low wall shear stress is always less important in

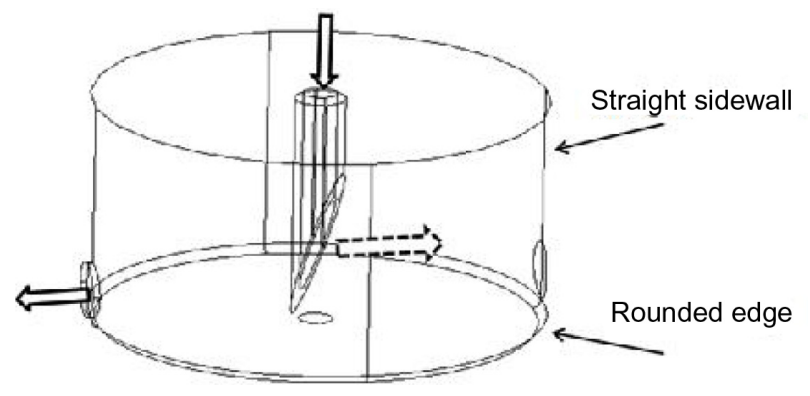

Figure 7 Tridimensional representation of the shape of a straight sidewall cavity with a rounded edge.

Note: The arrow with the dotted lines indicates the direction of the needle bevel opening. The arrows in solid lines indicate the direction of inlet and outlet flows.

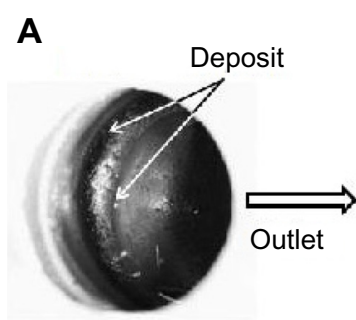

Inner straight sidewall

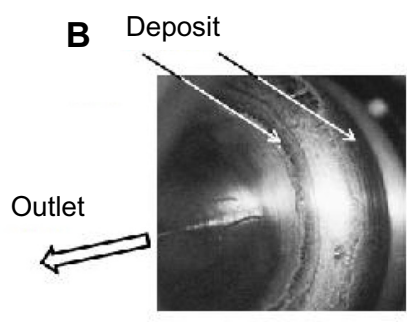

Inner rounded sidewall
Figure 8 Magnified photo of the inner edge of a straight sidewall cavity and rounded sidewall cavity.

Notes: Straight sidewall cavity $(\mathbf{A})$ and rounded sidewall cavity, Vortex ${ }^{\circledR}$ TR Low Profile (B). The thin arrows indicate the deposit on the inner surfaces and the thick arrows indicate the direction of outlet flow.

a curved sidewall cavity than in a straight sidewall cavity. A particular case for a straight sidewall cavity was tested in the simulations in which a rounded edge was substituted for the sharp angle in the cavity (Figure 7). The numerical results show that the suppression of sharp angles is a positive factor for improving the flushing efficiency by reducing the fraction of the inner surface for which the wall shear stress is insufficient for effective flushing.

The reason for such a result can be seen in the repartition of the lines of flow, which shows the importance of the wall friction in the port. In a curved sidewall port, the lines of flow can follow the surfaces that have sufficient friction for effective flushing. In a straight sidewall port, the sharp surface angles can promote a local recirculating flow and a drastic diminution of the local wall friction, thereby reducing the efficiency of flushing.

\section{Conclusion}

The implementation of totally implantable devices is now widely used in various fields of application, such as oncology, nutrition, and antibacterial therapies. ${ }^{15-19}$ Many studies have been devoted to the evaluation of these devices with the objective of assessing possible risk factors and medical complications, such as infections or obstruction. Most of these studies highlight difficulties that are related to protocols or patients.

Some reports ${ }^{15-18}$ list a range of difficulties encountered in the insertion and use of totally implanted devices. The complications reported in the literature correspond to a wide range of causes. Thus, the positioning of the catheter may prevent thrombotic complications, and the use of an open, venous cut-down technique with fluoroscopic control may allow any immediate intrathoracic complications to be avoided. ${ }^{15,16}$ Complications associated with the percutaneous puncture technique are also reported. ${ }^{17}$ For some authors, an interval of at least 8 days between placement of the TIVAD and the first use of these devices may be advisable 
to reduce complications. ${ }^{18}$ However, the agreement on this rule is not unanimous.

In many cases, it is recognized that strict and repeated flushing protocols are key to ensure the potency and durability of the implanted devices. A newly designed Vortex ${ }^{\circledR}$ VX port with a tangential outlet should allow for better clearance of the chamber, and it should thus reduce the occlusion of the device. ${ }^{19}$ It was the aim of this study to focus attention on the possible impact of the cavity shape. From this point of view, we believe that the implementation of curved sidewall cavities would be a positive factor, allowing for better maintenance and, thus, a lower occurrence of complications. This view is based on the experimental results shown in Figure 2. The numerical simulations demonstrate a consistent range of indicators for understanding the role of the flow in a cavity. Examining the deposit in cavities after they are flushed provides additional information. The deposit can easily be made visible by coloring proteins (Coomassie stains). After septum removal, magnified pictures can be obtained that show the inner cavity.

Figure 8A and B show the bottom parts of the cavities opposite to the outlet after one flushing with a $10 \mathrm{~mL}$ syringe under the conditions previously described. The deposit areas observed on the pictures correlate with the results of the numerical simulations (Figure 6A and B). First of all, one can observe that the area of the polluted part is smaller in the case of rounded sidewall cavity; this is consistent with the numerical results (Figure 6A, B and Table 1). Moreover, it is seen that in both cases, the deposits are preferentially located between the sidewall and either the base or the septum in the vicinity of sharp angles in cavities (Figure 6A and B).

A careful examination of the inner volumes of the implantable ports shows the existence of important sharp angles or surface irregularities at the connections between the lateral walls and either the basal surface or the septum. The point to be highlighted is that each surface "incident" (surface irregularity) may become a preferential point of deposit because of hydrodynamic conditions leading to sustainable pollution in the cavity.

A further consequence can be deduced from both the experimental results and numerical simulation. The improvement of the flushing is clearly due to a better distribution of higher values of the shear stress when a rounded edge wall cavity is used. Because the same process occurs during the perfusate injection, a reduction in the amount of deposit is possible.

We, the authors, hope that these considerations will be taken into account in the future in order to reduce the often unknown or underrated causes of complications inherent in the use of implantable ports. It is trivial that the mechanical and infectious complications related to the use of implantable devices are multifactorial. Any material improvement allows for an increase in the longevity of devices and a reduction of the medical, physical, psychological, and financial impacts of these complications.

\section{Acknowledgment}

The authors thank AngioDynamics for supplying the ports necessary for the study.

\section{Disclosure}

The authors report no conflicts of interest in this work.

\section{References}

1. Adler A, Yaniv I, Steinberg R, et al. Infectious complications of implantable ports and Hickman catheters in paediatric haematology-oncology patients. J Hosp Infect. 2006;62(3):358-365.

2. Ahmadi J, Izadyar M, Ashjaei B, et al. Study of advantages and disadvantages of totally implantable venous access device. Acta Medica Iranica. 2006;44(3):199-202.

3. Hall P, Cedermark B, Swedenborg J. Implantable catheter system for longterm intravenous chemotherapy. J Surg Oncol. 1989;41(1):39-41.

4. Herrmann KA, Waggershauser T, Sittek H, Reiser MF. Liver intraarterial chemotherapy: use of the femoral artery for percutaneous implantation of catheter-port systems. Radiology. 2000;215(1):294-299.

5. Hirota T, Yamagami T, Tanaka O, et al. Brain infarction after percutaneous implantation of port-catheter system via the left subclavian artery. Br J Radiol. 2002;75(898):799-804.

6. Yamagami T, Kato T, Iida S, Hirota T, Nishimura T. Management of end hole in placement of port-catheter system for continuous hepatic arterial infusion chemotherapy using the fixed catheter tip method. $A J R$ Am J. Roentgenol. 2005;184(4):1332-1339.

7. Yamagami T, Terayama K, Yoshimatsu R, Matsumoto T, Miura H, Nishimura T. Use of N-butyl cyanoacrylate in implantation of a port-catheter system for hepatic arterial infusion chemotherapy with the fixed-catheter-tip method: is it necessary? AJR Am J Roentgenol. 2008;191(5):1523-1529.

8. Matillon Y. [Quality assessment of the use and monitoring of implantable ports]. ANAES. 2001:1-57. French.

9. Baskin JL, Pui CH, Reiss U, et al. Management of occlusion and thrombosis associated with long-term indwelling central venous catheters. Lancet. 2009;374(9684):159-169.

10. Pittiruti M, Hamilton H, Biffi R, MacFie J, Pertkiewicz M . ESPEN guidelines on parenteral nutrition: central venous catheters (access, care, diagnosis and therapy of complications). Clin Nutr. 2009;28(4): 365-377.

11. Ragni MV, Journeycake JM, Brambilla DJ. Tissue plasminogen activator to prevent central venous access device infections: a systematic review of central venous access catheter thrombosis, infection, and thromboprophylaxis. Haemophilia. 2008;14(1):30-38.

12. Guiffant G, Durussel JJ, Merckx J, Flaud P, Vigier JP, Mousset P. Flushing of intravascular access devices (IVADs) - efficacy of pulsed and continuous infusions. J Vasc Access. 2012;13(1):75-78.

13. Guiffant G, Durussel JJ, Flaud P, Vigier JP, Merckx J. Flushing ports of totally implantable venous access devices, and impact of the Huber point needle bevel orientation: experimental tests and numerical computation. Med Devices (Auckl). 2012;5:31-37.

14. Guiffant G, Durussel JJ, Flaud P, Royon L, Marcy PY, Merckx J. Power port contrast medium flushing and trapping: impact of temperature, an in vitro experimental study. Med Devices (Aukl). 2013;6:133-140. 
15. Hartkamp A, van Boxtel AJ, Zonnenberg BA, Witteveen PO. Totally implantable venous access devices: evaluation of complications and a prospective comparative study of two different port systems. Neth $J$ Med. 2000;57(6):215-223.

16. Royle TJ, Davies RE, Gannon MX. Totally implantable venous access devices -20 years' experience of implantation in cystic fibrosis patients. Ann R Coll Surg Engl. 2008;90(8):679-684.

17. Tercier S, Gapany C, Diezi M, Clément C, Lemay K, Joseph JM. Incidents and complications of totally implanted vascular access devices in children: a prospective study. Patient Saf Surg. 2008;2(1):30.
18. Narducci F, Jean-Laurent M, Boulanger L, et al. Totally implantable venous access port systems and risk factors for complications: a oneyear prospective study in a cancer centre. Eur J Surg Oncol. 2011; 37(10):913-918.

19. Goossens GA, Verbeeck G, Moons P, Sermeus W, De Wever I, Stas M. Functional evaluation of conventional 'Celsite' venous ports versus 'Vortex' ports with a tangential outlet: a prospective randomised pilot study. Support Care Cancer. 2008;16(12):1367-1374.

\section{Publish your work in this journal}

Medical Devices: Evidence and Research is an international, peerreviewed, open access journal that focuses on the evidence, technology, research, and expert opinion supporting the use and application of medical devices in the diagnosis, treatment and management of clinical conditions and physiological processes. The identification of novel devices and optimal use of existing devices which will lead to improved clinical outcomes and more effective patient management and safety is a key feature. The manuscript management system is completely online and includes a quick and fair peer-review system. Visit http://www. dovepress.com/testimonials.php to read real quotes from authors.

Submit your manuscript here: http://www.dovepress.com/medical-devices-evidence-and-research-journal 